\title{
All cases of word production are not created equal: Reply to Costa and Santesteban
}

\section{Robert M. French and Maud Jacquet}

Department of Cognitive Science, University of Liège, Belgium

Although we are not necessarily in disagreement with the comment by Costa and Santesteban [1], neither are we as convinced as they are of the need for two modalities, one for word production, the other for word recognition. Their key claim is that in word production, it is the speaker who intentionally chooses the target language'. Perhaps at the moment of actually switching languages, one could argue for a need for a top-down intentional switching mechanism. But during most language production, simpler, automatic mechanisms of word activation - identical to those at work in word recognition - would suffice to keep the bilingual speaker in one or the other language. Each word in a particular language whether it is spoken or heard, activates a halo of other words - virtually all of which are in the same language - and, as a result, it requires no particular intentional effort for a bilingual to remain in that language. If you are having a financial discussion, it requires no intentional effort to remain in a financial context, as opposed to say, a culinary context. The same applies, we believe, for languages. It strikes us that the underlying mechanism of spreading activation suffices to explain (virtually) all of both word production as well as word recognition.

Further, throughout our article we emphasize the importance of the role of the task. In a task requiring you

Corresponding author: Robert M. French (rfrench@ulg.ac.be). to switch languages at the end of each sentence, there would, indeed, be a great deal of intentional effort involved in doing so and, in this case, Costa and Santesteban's point would certainly be correct. On the other hand, if you ask people to produce, as quickly as possible, the first word that comes to mind when they hear the utterance, 'What do cows drink?' they will produce 'milk', independently of any intentional desire to do so. This could reasonably be called non-intentional (bottom-up) word production.

Our point is that, although we are certainly not opposed to different mechanisms or combinations of processes for word production and word recognition, the case for this has to be made empirically. It is not enough simply to state the necessity of intentionality in specific-language word production and then conclude that this implies the existence of separate word production and word recognition mechanisms (i.e. different combinations of processes occurring in word perception compared with word production). In short, all cases of word production are not created equal.

\section{References}

1 Costa, A. and Santesteban, M. (2004) Bilingual word perception and production: two sides of the same coin? Trends Cogn. Sci. 8, 253

1364-6613/\$ - see front matter () 2004 Elsevier Ltd. All rights reserved. doi:10.1016/j.tics.2004.04.009

The pages of Trends in Cognitive Sciences provide a unique forum for debate for all cognitive scientists. Our Opinion section features articles that present a personal viewpoint on a research topic, and the Letters page welcomes responses to any of the articles in previous issues. If you would like to respond to the issues raised in this month's Trends in Cognitive Sciences or, alternatively, if you think there are topics that should be featured in the Opinion section, please write to: 